\title{
An Improved Design of Pressure Relay Based on Optical Switch
}

\author{
Shan CHEN*, Jun-chun MA, Feng LI, Xiao-guang YAO and Da-zhi CAO \\ Research Inst. of High-tech Hongqing Town \\ Xi'an, Shanxi, China \\ *chenshan1223@126.com
}

\begin{abstract}
This paper proposed one kind of improved design of pressure relay based on optical switch aiming at the problem with pressure relay, for example as large switching value, large deviation of set point, low repeatability, etc. Firstly, the structure and principium of pressure relay was analyzed, also the problems when using which was analyzed. Secondly, the structure and relating circuit of pressure relay was improved by setting the value of pressure with the reflective optical switch based on the precision pressure gauge. Experimental results of comparing test shows that it was obviously reduced with the switching value, repeatability and set point deviation when using pressure relay based on optical switch. The improving method proposed in this paper was feasible.
\end{abstract}

\section{Keywords- Optical switch; Pressure relay; Improved design}

\section{INTRODUCTION}

For the hydraulic equipment, in order to achieve automatic control using the pressure as control signal, the pressure relay was one of the important components. It was an electro-hydraulic control element, which converts the pressure signal of oil into electric signal. However, the original pressure relay had many problems such as the switching value was too large, the set point deviation was too big, the repetitive precision was too low and so on, which affected the reliability and safety of the hydraulic system [12]. In the process of technical measurement, because mechanical pressure gauges' elastic sensitive components had the high mechanical strength and the convenience of production, which made the mechanical pressure gauges had been widely used. But mechanical pressure gauges couldn't convert pressure signals into electrical signal outputs.

Therefore, based on the working principle of the pressure relay, this paper reconstructed the mechanical pressure gauges, and implemented an improved pressure relay, which could not only accurately read the pressure value, but also reliably convert pressure values through electrical components into the control signal.

\section{THE STRUCTURE AND PRINCIPIUM OF PRESSURE}

\section{RELAY AND THE ANALYSIS OF ITS MISTAKE OPERATION}

In the hydraulic system, through converting the oil pressure signal into electrical signals, the pressure relay can control the electromagnet, relays and other components, so that the oil circuit can perform the specified sequence of actions, and can also make the system stop working to protect the system security. The pressure relay is mainly consist of the pressure - displacement conversion mechanism, the electrical micro-switches and so on.

The mistake operation of the pressure relay can be summarized with large switching value, big set point deviation, low repetitive precision, etc. and the reasons of mistake operation are mainly as the follows [3-4].

1 . The bias cooperation with the plunger and the sleeve hole makes the pressure relay working abnormally.

2. The film was burst when working at long time, which made the pressure oil streaming from the cooperation gap between the plunger and the sleeve hole. This made the pressure relay working abnormally.

3. The micro-switch existed position bias when it was encountered in the actual operating, which made the pressure relay working abnormally.

4. The micro-switch worked abnormally by elasticity reducing of reed, which made the pressure relay working abnormally.

5. The lever rotation was not flexible when the adjustment screw adjusted improperly, which made the pressure relay working abnormally.

\section{IMPROVED DESIGN OF PRESSURE RELAy BASED ON OPTICAL SWITCH}

This paper proposed a method of improving pressure relay (shown as Figure.1). A reflection optical switch was added to the precision pressure gauge (shown as Figure.2) [5-6]. The reflection optical switch was fixed to the circular guide (shown as Figure.3). A carbon battery with 9V supplied the power to the reflection optical switch, whose output signal flowed into the relay (shown as Figure.4).

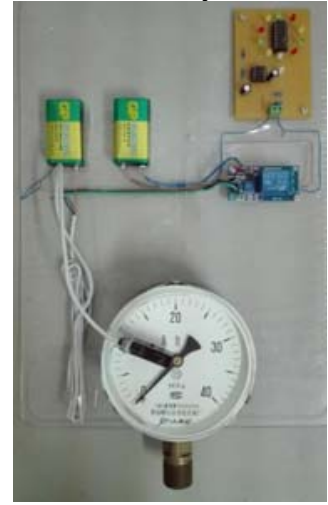

Figure 1. The overall design 


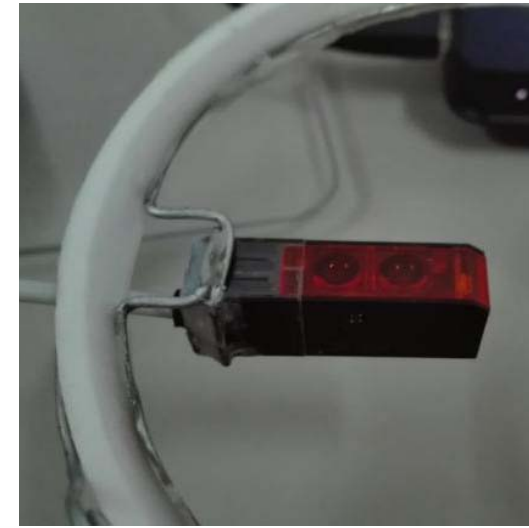

Figure 2. Reflective optical switch

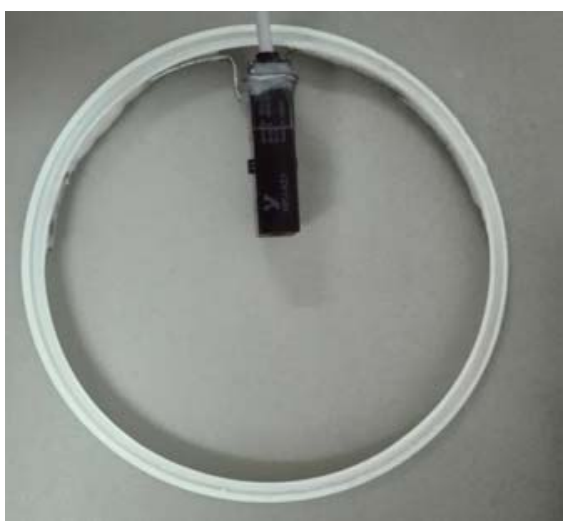

Figure 3. Circular guide

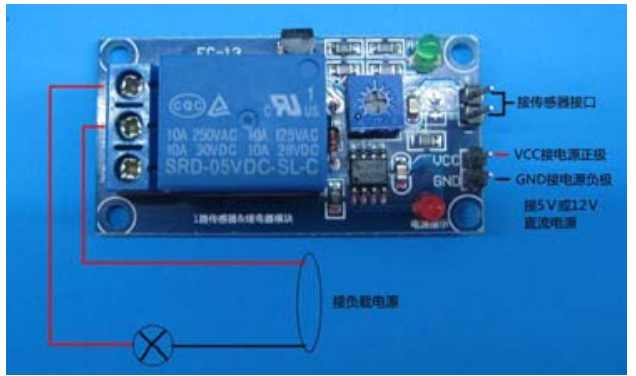

Figure 4. Relay

Pressure value was set by reflective optical switch with improving structure as follows. Firstly, optical switch was installed in the circular guide rail outside the precision gauge. Secondly, reflective optical switch could stop stably in any position on the guide, so that the set pressure value could be red exactly. Thirdly, when the pressure gauge instruction pointer turned to the center of optical switch, the optical path was blocked, which sent a pulse signal and transmitted to the relay, working circuit was controlled.

The parameters of reflective optical switch was as follows.

$>$ Light source was infrared light-emitting diode (860nm of light-emitting wavelength).

$>$ Current consumption was 30mA or less.
> Protection circuit were reverse power protection, output short circuit protection and output reverse connection protection.

$>$ Response time was1ms or less at action and reset response.

$>$ Shell material was PBT.

$>$ Lens material was denatured polyarylate.

When the vibration sensor didn't vibrate, the relay pulled in and the green light turned on, which showed that the common terminal was connected to the normal open terminal. When the vibration sensor was vibrated, the relay pulled out and the green light turned off, which showed that the common terminal was connected to the normal closed terminal.

The electrical parameters was as follows.

$>$ Supply voltage was 5VDC.

Current was greater than $100 \mathrm{~mA}$.

$>$ Load was 250V 10A AC or 30V 10A DC

\section{EXPERIMENTAL RESULTS AND ANALYSIS}

In order to verify whether the sensitivity to the voltage change of the improved pressure relay was improved, the experiment of testing to upper and lower switching values of the pressure relay was made in this paper, whose test circuit was shown as Figure.5. The experimental results were shown in Table.1 and Table.2. In the experiment, the type of PF$\mathrm{B} 8 \mathrm{H} 4$ pressure relay was used. The test environment was as follows. the test tool was pressure gauge with the precision of 0.25 , the working medium was hydraulic oil with N10, the temperature was $50^{\circ} \mathrm{C} \pm 2^{\circ} \mathrm{C}$.

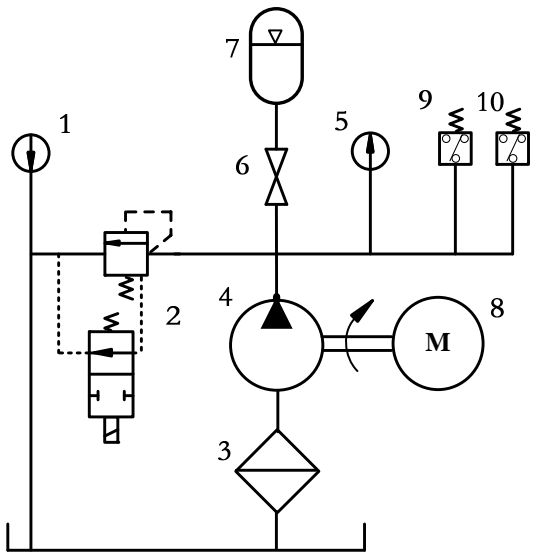

Figure 5. The overall design

1- Thermometer; 2- Electromagnetic relief valve 3- Filter; 4- Hydraulic pump; 5- Precision pressure gauge 6- Stop valve; 7- Accumulator; 8- Motor 9- Pressure relay of upper limit point 10- Pressure relay of lower limit point 
TABLE I. TEST RESULTS OF THE ORIGINAL PRESSURE RELAY

\begin{tabular}{|c|c|c|c|c|}
\hline \multirow{2}{*}{$\begin{array}{c}\text { The Set Point } \\
\text { Value Mpa }\end{array}$} & \multicolumn{2}{|c|}{17} & \multicolumn{2}{c|}{14} \\
\hline \multirow{2}{*}{$\begin{array}{c}\text { The Upper } \\
\text { Switching Value } \\
\text { Mpa }\end{array}$} & 16.63 & 16.58 & 13.73 & 13.26 \\
\cline { 2 - 5 } & 16.20 & 16.02 & 13.23 & 13.15 \\
\cline { 2 - 5 } & 16.07 & 16.48 & 13.06 & 13.13 \\
\hline $\begin{array}{c}\text { Average Value } \\
\text { Mpa }\end{array}$ & 16.30 & 16.36 & 13.34 & 13.18 \\
\hline Repeatability\% & 1.6 & 1.6 & 1.9 & 0.37 \\
\hline $\begin{array}{c}\text { The Lower } \\
\text { Switching Value } \\
\text { Mpa }\end{array}$ & 17.17 & 17.02 & 14.06 & 14.36 \\
\cline { 2 - 5 } & 17.45 & 17.18 & 14.15 & 14.39 \\
\hline $\begin{array}{c}\text { Average Value } \\
\text { Mpa }\end{array}$ & 17.42 & 17.24 & 14.31 & 14.26 \\
\hline Repeatability \% & 1.3 & 1.4 & 1.9 & 1.0 \\
\hline \multirow{2}{*}{$\begin{array}{c}\text { The Upper } \\
\text { Deviation of The }\end{array}$} & $\begin{array}{c}\text { Switching Value Of } \\
\text { Set Point Control }\end{array}$ & $\begin{array}{c}\text { Switching Value Of } \\
\text { Set Point Control }\end{array}$ \\
\cline { 2 - 5 } & \multicolumn{2}{|c|}{1.2} & 0.68 & \multicolumn{2}{|c|}{0.59} & 0.55 \\
\hline
\end{tabular}

TABLE II. TEST RESULTS OF PRESSURE RELAY BASED ON OPTICAL SWITCH

\begin{tabular}{|c|c|c|c|c|}
\hline \multirow{2}{*}{$\begin{array}{c}\text { The Set Point } \\
\text { Value Mpa }\end{array}$} & \multicolumn{2}{|c|}{17} & \multicolumn{2}{c|}{14} \\
\hline \multirow{2}{*}{$\begin{array}{c}\text { The Upper } \\
\text { Switching Value } \\
\text { Mpa }\end{array}$} & 16.88 & 16.90 & 13.79 & 13.87 \\
\cline { 2 - 5 } & 16.50 & 16.62 & 13.76 & 13.75 \\
\cline { 2 - 5 } & 16.81 & 16.74 & 13.84 & 13.91 \\
\hline $\begin{array}{c}\text { Average Value } \\
\text { Mpa }\end{array}$ & 16.73 & 16.75 & 13.79 & 13.84 \\
\hline Repeatability\% & 1.08 & 0.80 & 0.23 & 0.45 \\
\hline $\begin{array}{c}\text { The Lower } \\
\text { Switching Value } \\
\text { Mpa }\end{array}$ & 17.05 & 17.18 & 14.02 & 14.01 \\
\cline { 2 - 5 } & 17.14 & 17.03 & 14.22 & 14.11 \\
\hline $\begin{array}{c}\text { Average Value } \\
\text { Mpa }\end{array}$ & 17.13 & 17.11 & 14.19 & 14.09 \\
\hline Repeatability \% & 0.46 & 0.43 & 0.91 & 0.43 \\
\hline $\begin{array}{c}\text { Deviation Of The } \\
\text { Set \% }\end{array}$ & $\begin{array}{c}\text { Twitching Value Of } \\
\text { Set Point Control }\end{array}$ & $\begin{array}{c}\text { Switching Value Of } \\
\text { Set Point Control }\end{array}$ \\
\hline
\end{tabular}

\begin{tabular}{|l|l|l|l|l|}
\hline & 0.38 & 0.31 & 0.55 & 0.27 \\
\hline
\end{tabular}

Experimental results of comparing test showed that it obviously reduced with the switching value, repeatability and set point deviation when using pressure relay based on optical switch. The improving method proposed in this paper was feasible.

\section{CONCLUSION}

This paper analyzed the working principle and structural characteristics of the mechanical pressure gauge, improved pressure gauge, proposed an improving design scheme of the pressure relay based on optical switch. Compared with the traditional pressure relay, it could be concluded that the improved pressure relay could not only overcome the problems existing in the traditional pressure relay, but also reduce the set point deviation and improve the measurement accuracy greatly.

\section{REFERENCES}

[1] LIU Bao-jie, YANG Qing-wen, WU Xiang. Current Research and Development Trend of Fault Diagnosis Technology for Hydraulic System [J]. Hydraulics Pneumatics \& Seals, 2016, 08: 68-71.

[2] ZHANG Li. Evaluation of Vncertainty about Indication Error of Electric Contact Filled System Thermoneter in Result of Measurement [J]. Metrology \& Measurement Technique,2009, 36(5): 88-89.

[3] XU Yi1, YANG Zhengrui, WANG Yinghong, WEN Jiquan. Computer- aided Test \& Control System of Hydraulic PressureCompensatory and Pressure- Relay [J]. Hydromechatronics Engineering, 2004, 04: 161-162.

[4] ZHAO Xianqiong, LIU Yilun, YANG Xiaohong, HU Suyun. Research on Pressure Relay of New Type with Dif ferential Pressure [J]. Journal of Changsha Communications University, 2002, 18(1): 18-21.

[5] Bach im B L, Ogunsola O O, Gaylord T K. Optical-fiber to waveguide coupling using carbon-diox ide-laser induced long period fiber gratings [J]. Optics Lette rs, 2005, (30): 2080- 2082.

[6] DING Fangli. Implementation of a Kind of Photoelectric Switch with Diffuse Relflection [J]. Journal of Huangshan University, 2006, 8(3): 31-34. 